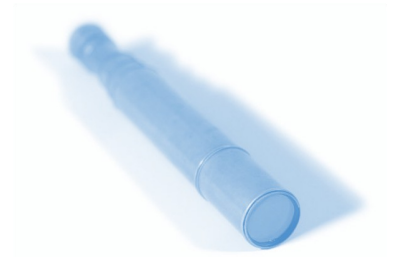

\author{
Kate Slaughter and \\ Simon Bates \\ School of Physics and \\ Astronomy \\ University of Edinburgh \\ Edinburgh \\ EH9 3JZ \\ k.a.slaughter@sms.ed.ac.uk \\ s.p.bates@ed.ac.uk
}

The retention of students

in the STEM subjects is of great concern for universities, employers and the government.

\section{Mapping the transition - Content and pedagogy across the school-university boundary}

\begin{abstract}
The period of transition for students from school to university is of great importance, however it is also potentially fraught with difficulties. Incoming students are faced with a study environment very different to anything they have known before and often face a steep learning curve of new study skills and learning methods in order to keep afloat. Whilst these factors are well recognised and have been addressed in literature, there is a growing recognition of the fact that how students perceive their chosen subject has a large impact on how they perform. In fact it has been suggested that students' expectations of a subject may be better predictors of performance in tertiary education than the previous performance of students in school examinations.
\end{abstract}

This article looks at the application of the CLASS (Colorado Learning Attitudes about Science) Survey at the University of Edinburgh and in selected schools across the UK. The survey allows the opinions and perspectives of students to be compared to those of expert physicists and thus the students' levels of expert-like thinking to be gauged. At the University of Edinburgh the first year physics class, comprising of both Physics students and others taking physics as a complementary course, were surveyed before teaching began and again at the end of first year. In schools, students were surveyed towards the end of their last year of school.

\section{Introduction}

The retention of students in the STEM subjects is of great concern for universities, employers and the government. In the sciences a "leaky pipe" effect is seen with students dropping out at every stage of their degrees, although most commonly in the early years of their studies. This is especially prevalent in the first year at university where students are adapting to a very different style of teaching and learning.

There is evidence that the way students think about a subject has a profound effect on performance in that subject. It has been suggested that from as early as primary school children develop misconceptions which can shape their attitudes and beliefs of how they view science in general ${ }^{1}$. It has long been established that external social factors and stereotypes create a series of beliefs in students that can affect performance ${ }^{2}$. In fact it has been suggested in previous research that attitudes and beliefs may be a better indicator of their ability than examination results ${ }^{3}$. This has lead to increased research into students' attitudes and beliefs in a variety of subject disciplines.

In the area of Physics, one instrument that has been widely used to examine student attitudes is the Colorado Learning Attitudes about Science Survey (CLASS). This measures the attitudes and beliefs of university students through a series of attitudinal questions and calculates their level of "expert-like" thinking by comparing the answers to those of physics professors and other professional physicists. The survey has been used at many institutions across North America but has been far less widely adopted in the UK. The survey is usually administered both before and after a specific course is taught, or period of instruction, thus allowing the effect of the course on students' attitudes to be assessed through the shift in the students' answers.

The School of Physics and Astronomy at the University of Edinburgh has a very large first year class comprising students taking Physics degrees and those taking the course as an elective. It is a highly successful course, with positive student feedback and clear student gains in conceptual understanding, as evidenced by pre- and post- application of standard diagnostic tests. The students are taught using interactive lectures utilising personal response systems (or "clickers") and in weekly three hour workshops, encouraging group work and discussion about physics ideas and concepts. 


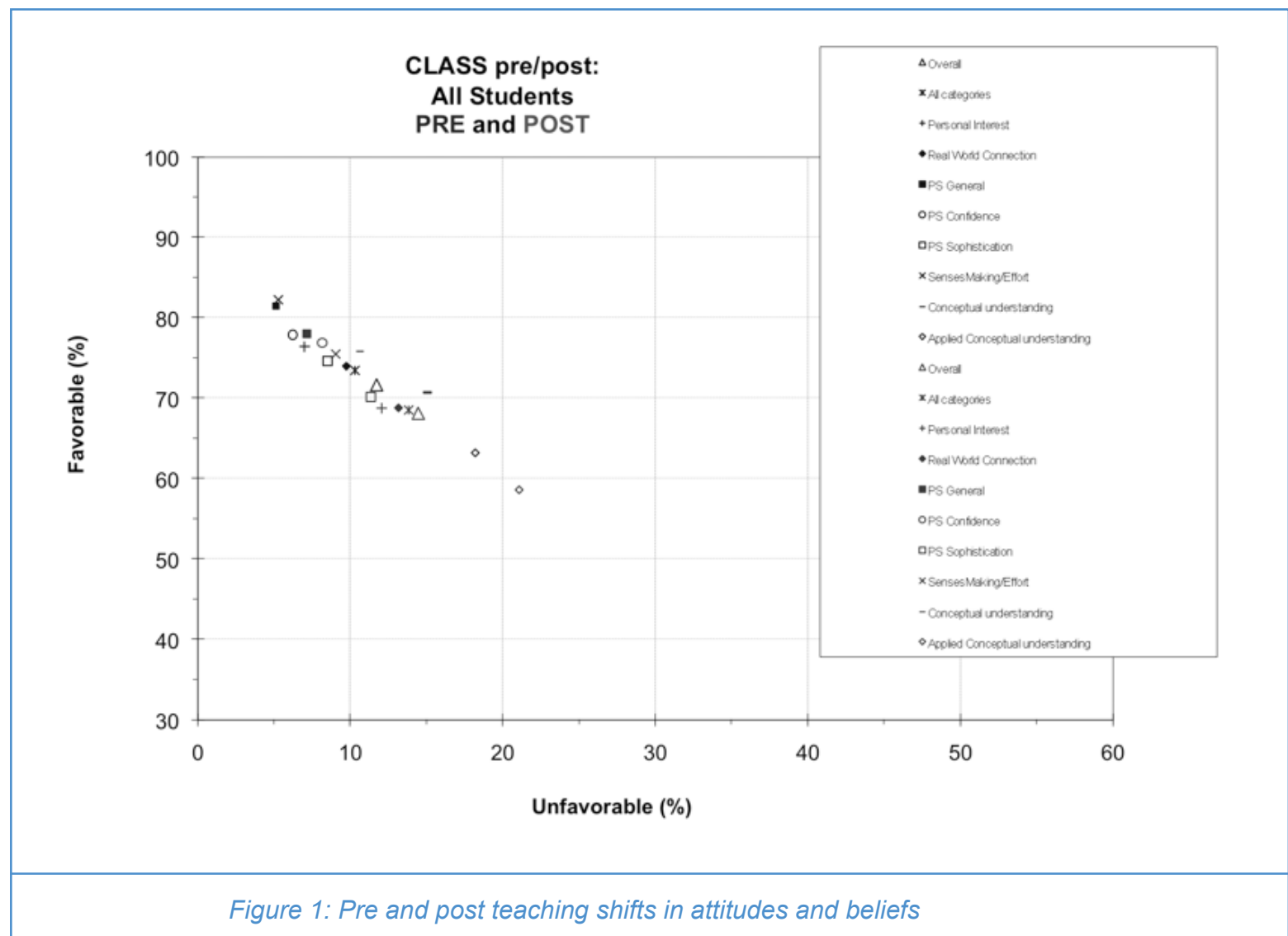

The class comprises over three hundred students. They are from a variety of educational backgrounds although the vast majority have either come or from the Scottish system of Highers and Advanced Highers or from the English, Welsh and Northern Irish school system of A levels. The incoming students have high examination results from school with all students having an A or B in physics and mathematics at the highest level studied.

\section{The CLASS Survey}

Based on a previous attitudinal survey, the Maryland Physics Experience survey (MPEX) ${ }^{4}$, CLASS has been developed by the Physics Education Research group at the University of Colorado $^{3}$. It consists of 42 statements, each of which is graded on a five point Likert scale, varying from strong agreement to strong disagreement with the statement. The questions are not a test of physics knowledge but of student attitudes and beliefs about the subject and how it is practiced. The questions are split into 8 categories which are as follows; Real world connections, Personal interest, Sense-making/ effort, Conceptual connections, Applied conceptual understanding, Problem solving (general), Problem solving sophistication and Problem solving confidence. Some questions can fall into several of the categories.

The survey has gone through rigorous processes to check its validity as an instrument. Amongst these are checks of the quality of the data - students must answer a "failsafe" question to ascertain if they are reading the questions and must also answer a certain percentage of the questions for their answers to be included. If the data fails either of these checks it is automatically discounted. The survey has been given to thousands of students across North America, both physics majors and non-physics majors. The survey was also given to academic staff at Colorado University to develop what was seen as an "Expert" response to the questions. Once a consensus had been reached this expert answer was used as a comparison to student responses in order for students' level of expert-like thinking to be calculated as a percentage.

Delivery of the survey is usually pre and post first year instruction so that the shifts in expert-like thinking are as a direct result of students' first year of university based learning. Nearly all published studies show that student "expertness" shows a marked decrease after a year of university study ${ }^{4}$.

\section{CLASS at Edinburgh}

The CLASS survey was given to all of the new students in their first week at the university and again in their last week of teaching. Of the 300 students enrolled in the course 150 students took both surveys and passed the data quality checks so all results shown are for a data set of 150. Each of the 42 individual questions was analysed for the whole class in order to show the shifts in expert-like thinking for the whole cohort.

The graph in Fig. 1 illustrates the results for all students and all question categories. It is sometimes referred to as 'an agree-disagree' plot, as it represents a measure of to what extent student responses agree (are favourable) or disagree (unfavourable) when compared to expert responses. If student responses were to become more favourable/ expert-like, there would be a shift towards the top left hand corner of the graph. The different shaped markers are for each of the eight categories mentioned previously. 
Simply from looking at the graph (Fig. 1) it can be seen that there is consistent decrease in the students' level of "expertness" across all categories.

Quantitatively, there is a change in their

favourable responses over all questions from $72 \%$ to $68 \%$, in the category on Personal Interest from $76 \%$ to $69 \%$ and in the category on Real world connection from $74 \%$ to $69 \%$ (Table 1.)

These results are however still high, pre and post instruction, compared to those seen in previous studies using the same instrument ${ }^{3}$. After discussion with one of the authors of the survey it is thought that these higher values reflect the differences between the North American and British education systems.

As mentioned previously each of the 42 statements was analysed for the whole class to determine the shift in attitude. It was then assessed as to whether these shifts were statistically significant rather than random variations in the mean to be expected in the sample. If it was found to be a significant shift the result was classed as either "Novice" or "Expert". If the students have become less expert they are classed as "Novice" and "Expert" if they have become more so. Out of 42 statements the class showed statistically significant shifts in 13 questions, becoming more novice-like in 11 questions and more expert in 2.
Fig. 2 shows the differences in the pre and post teaching results for just one of the statements showing a statistically significant shift towards Novice-like thinking, "The subject of Physics had little relation to what I experience in the real world". This is a statement that the expert response disagree with, however the first year students have shown a $10 \%$ increase in agreement.

The two questions the students became more expert-like in were both issues that are specifically addressed by the course design at Edinburgh. They were:

"To understand Physics I discuss it with friends and other students"

and

"It is possible to explain Physics without mathematical formulae"

The first statement is most likely a consequence of the collaborative working environment created by the workshop system at Edinburgh. The nature of the workshops means that the students have to discuss problems as a group and work on problem solving together. The course also requires students must be able to qualitatively explain all mathematics and calculations used: the students lose marks if they fail to do so.

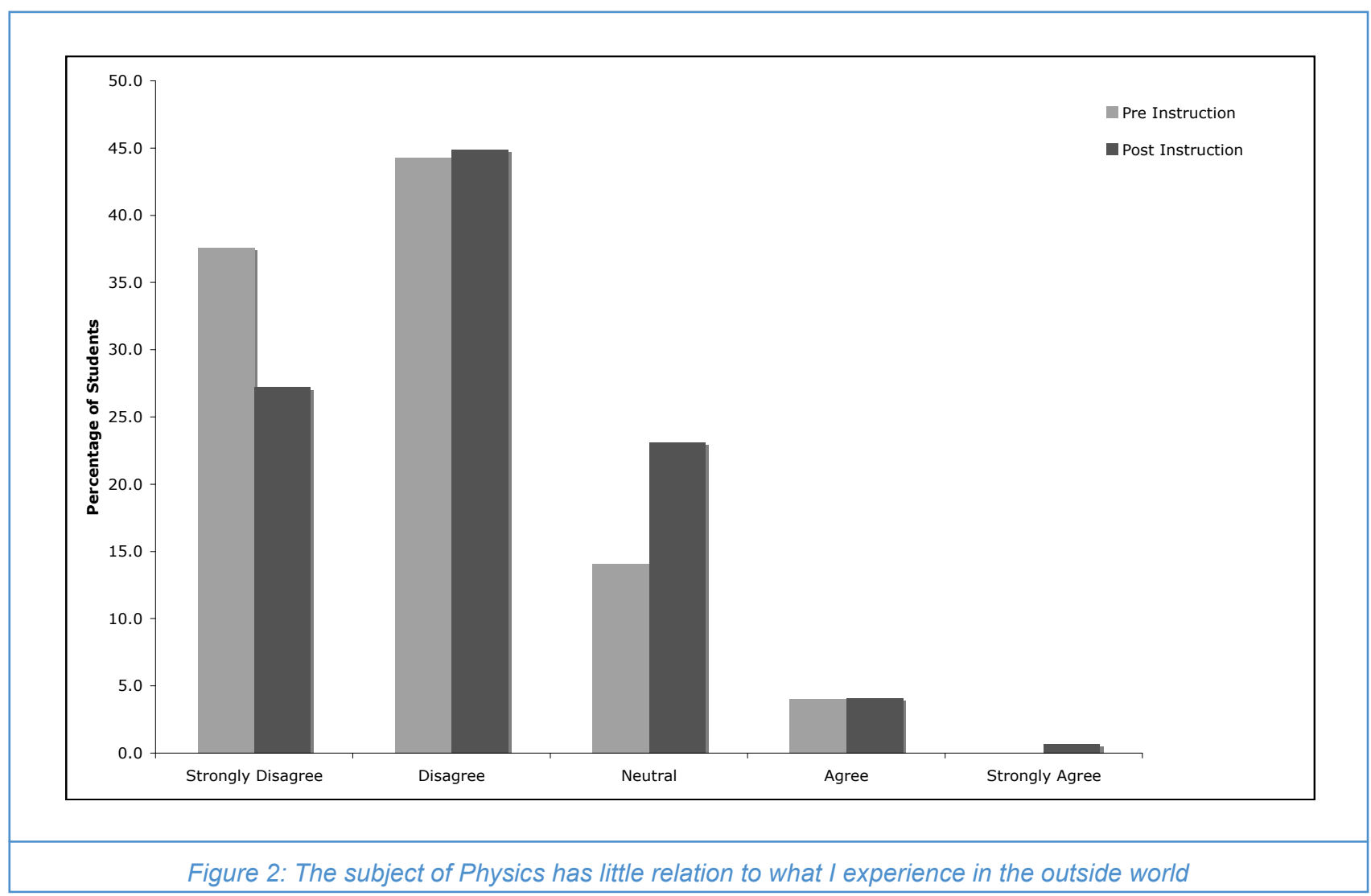


Further analysis was then carried out with the data in order to look at the differences between the physics majors and nonmajors and also the differences between male and female students.

In terms of degree choice it was shown that physics students do not show a statistically significant change in their levels of expert-like thinking. In contrast the non-majors showed a lower starting level (despite satisfying the same entry requirements as the physics majors) and a very significant drop in expert-like thinking over the same period of instruction. These results are illustrated in Figure 3.

\section{Conclusion}

The results of the CLASS survey at Edinburgh are very much in line with those recorded at other institutions that have completed the survey. A decline in the students' level of expert-like thinking is recorded in all of the eight categories of interest, including problem solving, personal interest and real world connections. Somewhat surprisingly, we have found that a course can be successful, provide clear student gains in conceptual understanding, be well received by students and still negatively affect students' attitudes and beliefs towards the subject.

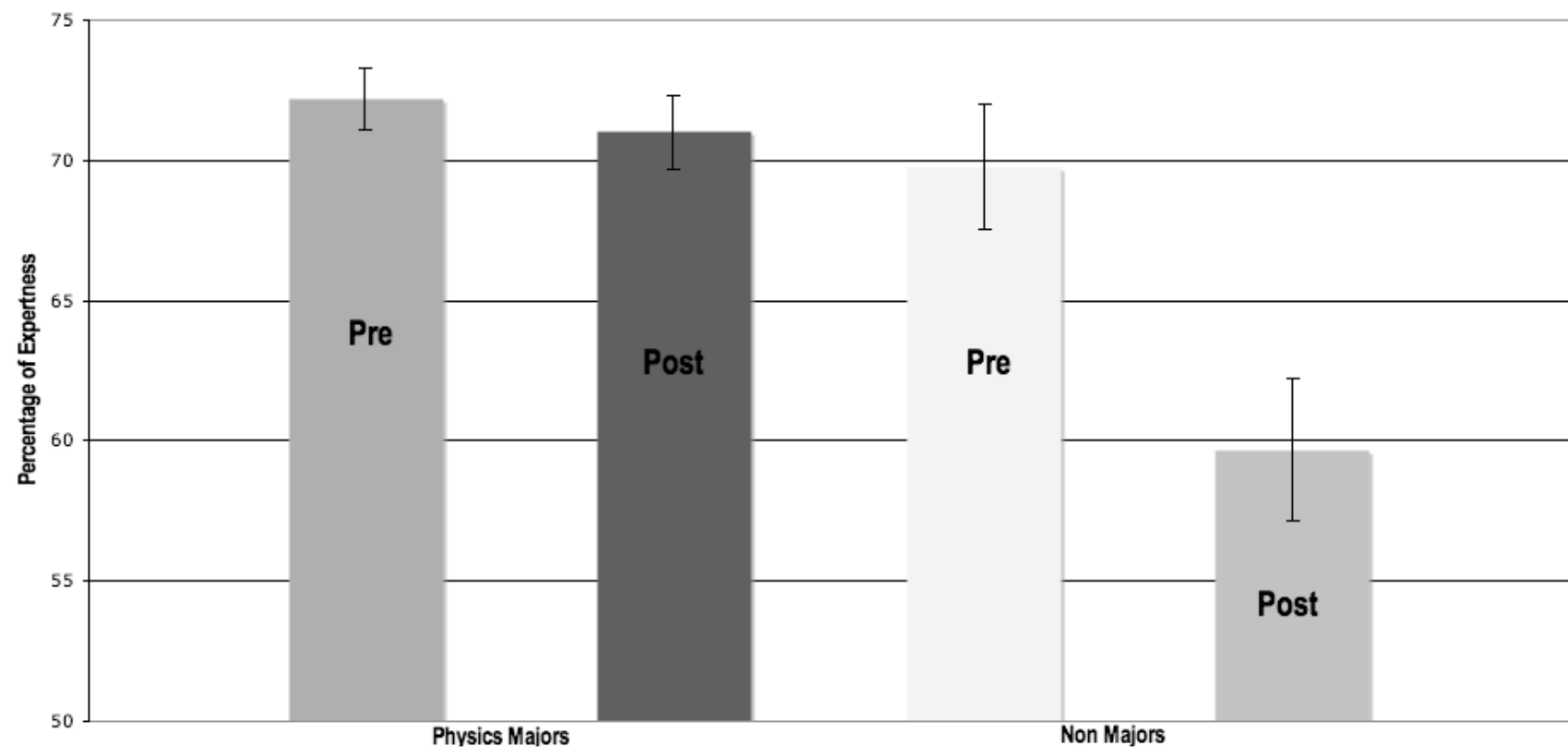

Figure 3: Physics majors and non-majors pre and post instruction

A similar effect was seen in the male-female split, with female students becoming less expert after instruction, although this effect was less pronounced.

\section{CLASS in Schools}

We also undertook the survey with school students in order to look their attitudes and belief. There have been no previous studies in this area thus there were no preconceived ideas as to what the results would show. All students surveyed were studying Higher or Advanced Higher physics at secondary schools across Scotland. Again a mixture of students intending to study physics at university and those who were not were surveyed.

Due to the difficulty of getting access to students to complete the survey and the time scales of the project it has not possible to carry out a pre and post teaching surveys. 170 students were surveyed once, in the months before their school leaving examinations. The results are currently being analysed.
Expanding on previous research we have looked in greater detail at the make up of the class and how specific groups are affected by the transition. We have seen that non-majors and female students show a drop in their levels of expert like thinking after a year of instruction.

The only areas where students' beliefs are not seen to decline are areas that have been specifically targeted by the course at Edinburgh. This leads to the question of whether we should be designing courses specifically to target these areas or is this part of the natural process of adjustment to university life and study. In an attempt to answer these question the project will be extended next year to poll final year student to gauge their levels of expert-like thinking.

Attitudes and beliefs are critical in determining a student's approach to learning a subjects however these are often overlooked in favour of grades when trying to predict the future success of students. Supporting the transition from tertiary to secondary education comes from being aware of these issues and, potentially, taking steps to address them in introductory level courses. 
Retention is a large problem for the sciences with students leaving courses throughout their degree. Many of those who do choose to leave find themselves feeling disillusioned with the courses, claiming it is not what they expected from school. Being able to identify where these drops in attitudes and beliefs lie means that they can be targeted, leading to more confident students and in the long term to greater retention of student numbers.

\section{Acknowledgements}

The support and assistance from James Gillespie's High School, Stewart Melville College and Ronna Montgomery is gratefully acknowledged. This work has been funded by the Principal's Teaching Award Scheme at the University of Edinburgh.

\section{References}

1. Linn, M. C., and Songer, N. B. (1991) Cognitive and conceptual change in adolescence Am. J. of Educ., 379-417

2. J S. Eccles and J E. Jacobs (1986) Social Forces Shape Math Attitudes and Performance Journal of Women in Culture and Society, 11, (2), 367-380

3. Adams, WK; Perkins, KK; Podolefsky, NS (2006) A new instrument for measuring student beliefs about physics and learning physics the Colorado Learning Attitudes about Science Survey Physical Review Special TopicsPhysics Education Research, 2, (1)

4. E. F. Redish (1996) The Distribution and Change of Student Expectations in Introductory Physics <www.physics.umd.edu/perg/papers/redish/icupeex.htm> Accessed 28/04/2009
Being able to identify where these drops in attitudes and beliefs lie means that they can be targeted, leading to more confident students and in the long term to greater retention of student numbers. 